\title{
Chronic obstructive pulmonary disease in patients with lung cancer: prevalence, impact and management challenges
}

This article was published in the following Dove Press journal:

Lung Cancer:Targets and Therapy

7 August 2017

Number of times this article has been viewed

\author{
Dionisios Spyratos \\ Eleni Papadaki \\ Sofia Lampaki \\ Theodoros Kontakiotis \\ Pulmonary Department, Lung Cancer \\ Oncology Unit, Aristotle University \\ of Thessaloniki, G. Papanicolaou \\ Hospital, Thessaloniki, Greece
}

\begin{abstract}
Chronic obstructive pulmonary disease (COPD) and lung cancer share a common etiological factor (cigarette smoking) and usually coexist in everyday clinical practice. The prevalence of COPD among newly diagnosed patients with lung cancer sometimes exceeds 50\%. COPD is an independent risk factor (2-4 times higher than non-COPD subjects) for lung cancer development. The presence of emphysema in addition to other factors (e.g., smoking history, age) could be incorporated into risk scores in order to define the most appropriate target group for lung cancer screening using low-dose computed tomography. Clinical management of patients with coexistence of COPD and lung cancer requires a multidisciplinary oncology board that includes a pulmonologist. Detailed evaluation (lung function tests, cardiopulmonary exercise test) and management (inhaled drugs, smoking cessation, pulmonary rehabilitation) of COPD should be taken into account for lung cancer treatment (surgical approach, radiotherapy).
\end{abstract}

Keywords: lung cancer, COPD, coexistence, risk factor, therapy decisions

\section{Introduction}

Chronic obstructive pulmonary disease (COPD) and lung cancer are among the most common causes of death worldwide, ${ }^{1}$ and as they have the same etiological factor (cigarette smoking) they usually coexist in everyday clinical practice. ${ }^{2}$ Lung cancer is the leading cause of cancer in the USA, even though it is the second in prevalence for both sexes. Recently published worldwide statistics showed that it is also the leading cause of cancer death among men and the second cause of cancer death among women. ${ }^{3}$ The 5 -year survival rates are quite disappointing (17.9\% for the USA), even though there is a statistically significant improvement during the last years $(-2.3 \%$ in mortality between 2004 and 2013). ${ }^{4}$ On the other hand, COPD is a common disease - especially among current/former smokers and the elderly - as it was estimated that $10 \%$ of adults $>40$ years old suffered from clinically important disease (spirometric stage II or higher). ${ }^{5}$ According to World Health Organization, COPD is the third leading cause of death worldwide accounting for 3.2 million of deaths in $2015 .^{6}$ The aim the present review article is to point out the treatment challenges of patients who suffer from lung cancer and COPD simultaneously.

\section{Prevalence of lung cancer among COPD patients and vice versa}

Long-standing, prospective studies of COPD patients evaluating the effect of inhaled drugs on mortality and lung function decline showed that lung cancer was among the
Correspondence: Dionisios Spyratos Pulmonary Department, Lung Cancer Oncology Unit, Aristotle University of Thessaloniki, G. Papanicolaou Hospital, Thessaloniki 57010, Greece Tel +306979490052

Email diospyrato@yahoo.gr 
most common cause of death. ${ }^{7,8}$ Several observational studies have concluded that COPD is an independent risk factor for the development of lung cancer. ${ }^{9-14}$ The relative risk of lung cancer presence seems to be higher among patients with emphysema compared to those with chronic bronchitis..$^{9,15}$ Additionally, the severity of airflow obstruction, as expressed by forced expiratory volume in 1 second $\left(\mathrm{FEV}_{1}\right)$, is associated with lung cancer development ${ }^{16}$ even though one study came to the opposite conclusion. ${ }^{11}$

Taking into account the common etiological factor (cigarette smoking) and possible interrelated pathogenetic pathways (chronic exposure of bronchoalveolar stem cells to pro-inflammatory cytokines, low respiratory clearance of carcinogenetic substances in patients with COPD, epithelial-mesenchymal transition, abnormal repair, oxidative stress, increased cellular proliferation, genomic and epigenomic changes), ${ }^{17,18}$ the percentage of patients with COPD is extremely high among patients with lung cancer. In a retrospective study among patients with newly diagnosed lung cancer, the prevalence of COPD was much higher for men $(72.8 \%)$ compared to women $(52.5 \%)$. It is important to notice that this difference remained after adjustment for age and number of pack-years for smoking (odds ratio [OR]: 0.48; 95\% CI: 0.28-0.83; $p=0.009) .{ }^{19}$ Additionally, in a comparative study between newly diagnosed patients with lung cancer and a matched controlled community-based population (according to age, sex and pack-year smoking exposure), the prevalence of COPD in individuals with and without lung cancer was $50 \%$ and $8 \%$, respectively (OR: 11.6, $p<0.0001)$. After adjustment for possible etiological variables, the prevalence of COPD in lung cancer cases was sixfold greater than in matched smokers. ${ }^{20}$

An incidence analysis from the UK General Practice Research Database during a 14-year period showed that lung cancer was four to five times more common among patients suffering from COPD in comparison with subjects without COPD, of the same age group and similar risk profile. ${ }^{10}$ During the BODE (Body Mass Index, Airflow Obstruction, Dyspnea, Exercise Performance) study, which was designed for identifying prognostic factors for COPD, 2,507 patients were followed-up for a median of 60 months, and 215 of them were diagnosed with lung cancer (incidence density of 16.7 cases per 1,000 person-years). ${ }^{11}$ The SYNERGY project aimed to investigate the relationship between previous respiratory diseases among patients with lung cancer. Emphysema was proved to be the strongest risk factor compared with other pulmonary diseases (bronchitis, pneumonia, tuberculosis and asthma) for lung cancer development (OR: 1.5 for men and 1.35 for women). ${ }^{9}$ A recent meta-analysis showed that only when emphysema was diagnosed qualitatively by a radiologist there was an increased risk for lung cancer but this association was lost if the diagnosis of emphysema was based on image analysis software. ${ }^{14} \mathrm{~A}$ possible explanation is that emphysema diagnosis by a radiologist probably reflects the most severe cases of the disease, which corresponds to higher burden of chronic inflammation and carcinogenesis.

\section{The impact of COPD on survival of lung cancer patients}

A long-standing (1991-2004) retrospective evaluation of $>4$ million patients enrolled in the UK General Practice Research Database showed that the 3-year survival for lung cancer patients with simultaneous diagnosis of COPD was almost half that of the general population $(15 \%$ vs $26 \% ; p<0.01) .{ }^{10}$ In a sample of 4,447 elderly lung cancer patients, the presence of COPD was associated with a decreased survival (hazard ratio [HR]: $1.14,95 \% \mathrm{CI}: 1.05-1.25)$ and the probability of surgical treatment or administration of chemotherapy was also lower. ${ }^{21}$ The presence of COPD and its severity have been proved to be significant prognostic factors for nonsmall-cell lung cancer (NSCLC) patients who underwent surgical treatment. ${ }^{22,23}$

A recent meta-analysis that included 26 studies (20012015 , only one was prospective, all the others were retrospective) estimated the effect of COPD on overall and disease-free survival among lung cancer patients. ${ }^{24}$ The HR was $1.19(95 \%$ CI: $1.10-1.25, p<0.00001)$ for overall survival and $1.52(95 \%$ CI: $1.04-2.23, p=0.03$ ) for disease-free survival. Studies that focused on patients with emphysema showed similar results even though the outcomes were less consistent because of a limited number of patients. Poorer prognosis was noticed independent of tumor staging, although the association was even stronger in early-stage disease (I-II). A recent, long-standing (30 years of follow-up) observational study from Finland showed that the severity of airway obstruction was associated with all-cause and lung cancer mortality. ${ }^{25}$ Sometimes, in the most severe cases of COPD, it is difficult to decide what the exact cause of death was but it is has been proved that the presence of both diseases has a negative effect on survival.

\section{The impact of COPD on lung cancer screening programs}

Taking into account the high incidence of lung cancer among patients with COPD, the effectiveness of screening programs might be increased if more subjects of this specific target 
group are included. The implementation of objective score scales would probably improve the diagnostic yield of screening programs. Recently, risk stratification scores have been developed in order to specify the target population for screening, and emphysema was included as an important parameter. De Torres et al validated the COPD Lung Cancer Screening Score that was based on age ( $>60$ years), body mass index $\left(<25 \mathrm{~kg} / \mathrm{m}^{2}\right)$, smoking history (>60 pack-years) and presence of emphysema on low-dose computed tomography (LDCT). They found that a score of 7-10 points was associated with a 3.5 -fold increase for lung cancer diagnosis. ${ }^{26}$ Using a risk prediction model based on clinical parameters and the presence of emphysema, the investigators of the National Lung Screening Trial classified participants into 5 quintiles. ${ }^{27}$ They found that subjects in the subgroup with highest risk for lung cancer death (quintiles: 3-5) accounted for almost $90 \%$ of the screening-prevented lung cancer deaths, while the number needed to screen in order to prevent one death due to lung cancer was much lower among participants in the upper quintile (number needed to screen: 5,276 vs 161 for Q1 and Q5, respectively). Criteria for participation in screening programs might be that symptomatic smokers regardless of age should undergo spirometry while elderly heavy smokers with or without symptoms should be offered LDCT. Those who are diagnosed with COPD (spirometry) and/or emphysema (LDCT) and achieve increased scores in risk stratification models should be considered as a high-risk group for lung cancer development and more often follow-up might be indicated. ${ }^{28,29}$

Results from observational studies among COPD patients suggest the potential protective role of inhaled corticosteroids (ICS) against lung cancer - particularly at high doses - but small randomized trials did not come to the same conclusions. ${ }^{30}$ A recent, retrospective, population-based study showed that treatment with specific statins was related with a significant chemopreventive effect against lung cancer in COPD patients in a dose-dependent manner. ${ }^{31}$

\section{Management challenges: COPD as a limitation for radiotherapy}

Preoperative assessment of pulmonary function by measuring $\mathrm{FEV}_{1}$ and diffusion capacity (DLco) is considered necessary. Recent guidelines recommend that if predicted postoperative (PPO) $\mathrm{FEV}_{1}$ and/or PPO DLco are $<30 \%$ pred., then cardiopulmonary exercise testing is essential in order to calculate the surgical risk and decide about treatment plan. ${ }^{32,33}$ Taking into account the above recommendation, patients with severe COPD (preoperative $\mathrm{FEV}_{1}<50 \%$ pred.) are defined as high-risk group and surgical treatment of lung cancer is contraindicated in many cases. Stereotactic body radiotherapy (SBRT) is a new treatment option for such patients with early-stage lung cancer. ${ }^{34}$ Stereotactic radiotherapy consists of 3-5 fractionations of highly prescribed doses (e.g., total dose of 36-54 Gy in 3-5 fractions) that are directed to small planning target volume. Retrospective and nonrandomized studies that included patients with inoperable disease or those who refused the surgical approach showed that local control, recurrence rates and overall survival are comparable with surgical series. ${ }^{35-40}$ A recent pooled analysis of two small randomized trials (58 patients), which closed early because of slow accrual, showed that stereotactic ablative radiotherapy (SART) was associated with increased 3-year survival compared with lobectomy (HR: 0.14, 95\% CI: $0.017-1.190, p=0.037)$ in patients with operable stage I $(\leq 4$ $\mathrm{cm})$ NSCLC.$^{41}$ We should emphasize that patients with severe COPD, with or without cardiovascular comorbidities, usually die because of cardiopulmonary complications, so the lung cancer-specific rather than overall mortality should be taken into account for the effectiveness of SART.

Palma $^{42}$ in a single-institution cohort of 176 patients with severe COPD (FEV $<<50 \%$ pred.) achieved a 3 -year overall survival of $47 \%$. Three patients developed radiation pneumonitis of Grade 3 (one patient early $<6$ weeks after SBRT and two late $>6$ weeks). They also reviewed two surgical and two SBRT studies among patients with severe COPD (FEV $<40 \%-50 \%$ pred.) and found comparable long-term survival rates, with higher 30-day mortality for surgical series. A retrospective study from $\mathrm{Japan}^{43}$ that compared 74 non-COPD patients with 62 suffering from COPD who underwent SBRT concluded that even though there was no difference in lung cancer-specific survival, the presence of COPD was associated with radiation pneumonitis in the multivariate analysis. On the contrary, Takeda et a ${ }^{44}$ evaluating retrospectively 265 lung cancer patients who were treated with SBRT found that radiation pneumonitis was relatively milder among patients with severe COPD. Probably this could be attributed to lower radiation doses that were used for COPD patients. The same authors followed up patients who underwent SBRT using spirometry and found that COPD was not correlated with faster $\mathrm{FEV}_{1}$ decline. ${ }^{45}$ Guckenberger et $\mathrm{al}^{46}$ evaluated the effect of pulmonary function on the risk of pulmonary toxicity after SBRT. They retrospectively studied more than 400 patients from five international institutions with a wide range of $\mathrm{FEV}_{1}(29 \%-109 \%$ pred.) although there was not a subgroup analysis for COPD patients. They found that radiation-induced pneumonitis was not inversely related 
with pulmonary function tests. It was quite interesting that pulmonary function improved more for those with worst pretreatment measurements, an effect that is similar with lung volume reduction surgery (LVRS) for emphysema patients.

Conclusively, patients with early-stage, inoperable lung cancer due to COPD should be carefully evaluated for SBRT and closely followed up for the possibility of radiation pneumonitis. There is no recommended/optimal radiation dose for patients with severe COPD based on spirometric variables or other severity index scores. Even severe COPD is not an absolute contraindication for SBRT. Tumor size, location (peripheral vs central), dose per fraction and total dose are important factors that are related with the severity of radiation pneumonitis. It seems that prolonging the time period of SBRT - with the same number of fractions - might reduce the long-term adverse events, especially dyspnea. ${ }^{47}$ Conventional radical radiotherapy should be avoided if possible, because of lower effectiveness rates compared with SBRT based on published data but not head-to-head randomized studies. ${ }^{36,48}$

\section{Management challenges: COPD as a limitation for surgical treatment}

Surgical treatment (lobectomy plus mediastinal lymph node dissection) is considered the standard of care and most effective approach for the limited stage NSCLC. ${ }^{49}$ Taking into account the effect of COPD on survival ${ }^{50}$ and postoperative complications (three times more common compared with non-COPD patients) ${ }^{51}$ as well as the recommended absolute contraindications of surgical management based on lung function parameters, ${ }^{32,33}$ spirometric evaluation is considered one of the most important steps for preoperative assessment.

Even though previous guidelines of British Thoracic Society $^{52}$ recommend that no further respiratory function tests are required for a lobectomy if the post-bronchodilator $\mathrm{FEV}_{1}$ is $>1.5 \mathrm{~L}$ and for a pneumonectomy if the post-bronchodilator $\mathrm{FEV}_{1}$ is $>2.0 \mathrm{~L}$, most recent reports agree that both $\mathrm{FEV}_{1}$ and DLco are necessary as well as calculation of PPO values. Guidelines agree that preoperative $\mathrm{FEV}_{1}+$ preoperative DLco both $>80 \%$ pred., preoperative $\mathrm{VO}_{2} \max >75 \%$ pred. or $>20 \mathrm{~mL} / \mathrm{kg} / \mathrm{min}$ and PPO $\mathrm{FEV}_{1}+$ PPO DLco both $>60 \%$ pred. are considered safe cutoff points for pulmonary resection up to pneumonectomy. On the contrary, if preoperative or PPO $\mathrm{VO}_{2} \max$ is $<35 \%$ pred. or $<10 \mathrm{~mL} / \mathrm{kg} / \mathrm{min}$ then the patient is considered as high-risk and alternative therapeutic option should be considered (SBRT or chemotherapy plus radiotherapy). ${ }^{32,33}$ Also, patients with either or both PPO $\mathrm{FEV}_{1}$ and DLco $<30 \%$ pred. are considered as high-risk group and cardiopulmonary exercise testing is indicated for more detailed evaluation. Measurement of arterial blood gases is considered a routine in everyday clinical practice for patients with severe COPD or based on oximetry values, but hypercapnia ${ }^{53}$ or hypoxemia ${ }^{54}$ is not considered as absolute contraindications.

There are some treatment strategies (preoperatively and the choice of the surgical approach) that could decrease the risk of postoperative pulmonary complications. Even though it is well known that long-term bronchodilators and ICS reduce symptoms and prevent exacerbations of COPD,${ }^{55}$ there are no large-scale, randomized trials about the effect of inhaled drugs on the postoperative complications and survival. Optimizing treatment for COPD before lung cancer resection is considered the standard of care. ${ }^{56} \mathrm{~A}$ recent study about the effect of perioperative administration of ICS showed no association (advantageous or deleterious) with respiratory postoperative complications. ${ }^{57}$ Regarding smoking abstinence, it should be of at least 4-8 weeks before surgery in order to reduce significantly the incidence of pulmonary postoperative complications ${ }^{58,59}$ but $^{\mathrm{FEV}_{1}} 1$ year after operation was not different between those who quitted smoking $>$ or $<1$ month before surgery ${ }^{60}$ Concerning pulmonary rehabilitation, a study that included 27 COPD patients with marginal lung function for resection $\left(\mathrm{FEV}_{1}: 1.14 \pm 0.7\right.$ $\mathrm{L}, \mathrm{VO}_{2} \max <15 \mathrm{~mL} / \mathrm{kg} / \mathrm{min}$ ) who underwent an intense pulmonary rehabilitation program of 4-6 weeks (6 days/ week) showed significant improvements in $\mathrm{PaO}_{2}, \mathrm{FEV}_{1}$ and $\mathrm{VO}_{2} \max$, and eventually all of them were capable for lobectomy. ${ }^{61} \mathrm{~A}$ review on this topic that included small case series concluded that preoperative pulmonary rehabilitation could increase exercise capacity, as expressed by $\mathrm{VO}_{2} \max$, but the effect on pulmonary postoperative complications is not quite clear. ${ }^{62}$

The choices of surgical approach (video-assisted thoracoscopic surgery [VATS] vs open thoracotomy and lobectomy vs sigmentectomy) as well as performing LVRS simultaneously are important treatment decisions that should be discussed in a multidisciplinary oncology board. A matched controlled propensity analysis of 182 COPD patients who underwent VATS or open thoracotomy lobectomy showed that the former was associated with a lower incidence of pulmonary complications, shorter operation time and shorter length of hospital stay. ${ }^{63}$ A recent review about the comparison of VATS versus thoracotomy lobectomy among patients with limited lung function reserves (PPO FEV $1<40 \%-60 \%$ pred.) ascertained the lower incidence for pulmonary postoperative complications, length of hospital stay and better long-term survival. ${ }^{64}$ LVRS has been proved to be an effective 
treatment approach for COPD as it improves exercise capacity, lung function and survival, especially among patients with heterogeneous upper-lobe emphysema and low exercise capacity. ${ }^{65,66}$ Single-center studies showed that patients with lung cancer and severe emphysema (preoperative $\mathrm{FEV}_{1}$ : $29 \%-44 \%$ pred.) who underwent lobectomy alone (the specific pulmonary lobe had the worst emphysema score) or lung cancer resection plus LVRS improved their lung function postoperatively. ${ }^{67,68}$ There is some evidence that the presence of airway obstruction preoperatively is related with better preservation of postoperative lung function than healthy subjects, even among the elderly. ${ }^{69,70}$ Bronchopleural fistula and prolonged hospitalization due to inability of early chest tube removal after lung cancer surgery are a quite common complications for COPD patients. ${ }^{71}$

There is no data concerning the effectiveness and adverse events of chemotherapy among COPD patients with lung cancer. There is evidence that epidermal growth factor receptor mutations are detected less commonly among patients with concomitant emphysema. ${ }^{72,73}$

\section{Conclusions}

Lung cancer and COPD usually coexist in everyday clinical practice. COPD is an independent risk factor for the development of lung cancer. COPD is a negative prognostic factor for lung cancer patients. The presence of COPD may alter the treatment plan (radiotherapy, surgical approach) for lung cancer.

\section{Disclosure}

The authors report no conflicts of interest in this work.

\section{References}

1. Murray CJ, Lopez AD. Measuring the global burden of disease. N Engl J Med. 2013;369(5):448-457.

2. Wilson DO, Weissfeld JL, Balkan A, et al. Association of radiographic emphysema and airflow obstruction with lung cancer. Am J Respir Crit Care Med. 2008;178(7):738-744.

3. Torre LA, Siegel RL, Jemal A. Lung cancer statistics. Adv Exp Med Biol. 2016;893:1-19.

4. Howlader N, Noone AM, Krapcho, M et al. SEER Cancer Statistics Review, 1975-2013, National Cancer Institute. Bethesda, MD, Available from: http://seer.cancer.gov/csr/1975_2013/, based on November 2015 SEER data submission, posted to the SEER web site, April 2016.

5. Buist AS, McBurnie MA, Vollmer WM et al. International variation in the prevalence of COPD (the BOLD study): a population-based prevalence study. Lancet. 2007;370(9589):741-750.

6. World Health Organization. The top 10 causes of death. Available from: http://www.who.int/mediacentre/factsheets/fs310/en/. Accessed March 2016.

7. Calverley PM, Anderson JA, Celli B, et al. Salmeterol and fluticasone propionate and survival in chronic obstructive pulmonary disease. N Engl J Med. 2007;356(8):775-789.
8. Tashkin DP, Celli B, Senn S, et al. A 4-year trial of tiotropium in chronic obstructive pulmonary disease. $N$ Engl J Med. 2008;359:1543-1554.

9. Denholm R, Schüz J, Straif K, et al. Is previous respiratory disease a risk factor for lung cancer? Am J Respir Crit Care Med. 2014;190(5):549-559.

10. Kiri VA, Sorianob JB, Visickc G, Fabbri LM. Recent trends in lung cancer and its association with COPD: an analysis using the UK GP Research Database. Prim Care Resp J. 2010;19(1):57-61

11. de Torres JP, Marin JM, Casanova C, et al. Lung cancer in patients with chronic obstructive pulmonary disease. Incidence and predicting factors. Am J Respir Crit Care Med. 2011;184(8):913-919.

12. Anthonisen NR, Skeans MA, Wise RA, Manfreda J, Kanner RE, Connett JE; Lung Health Study Research Group. The effects of a smoking cessation intervention on 14.5-year mortality: a randomized clinical trial. Ann Intern Med. 2005;142(4):233-239.

13. Mannino DM, Aguayo SM, Petty TL, et al. Low lung function and incident lung cancer in the United States: data from the First National Health and Nutrition Examination Survey follow-up. Arch Intern Med. 2003;163(12):1475-1480.

14. Smith BM, Pinto L, Ezer N, et al. Emphysema detected on computed tomography and risk of lung cancer: a systematic review and metaanalysis. Lung Cancer. 2012;77(1):58-63.

15. de Torres JP, Bastarrika G, Wisnivesky JP, et al. Assessing the relationship between lung cancer risk and emphysema detected on low-dose CT of the chest. Chest. 2007;132(6):1932-1938.

16. Wasswa-Kintu S, Gan WQ, Man SF, et al. Relationship between reduced forced expiratory volume in one second and the risk of lung cancer: a systematic review and meta-analysis. Thorax. 2005;60(7):570-575.

17. Yang IA, Relan V, Wright CM, et al. Common pathogenic mechanisms and pathways in the development of COPD and lung cancer. Expert Opin Ther Targets. 2011;15(4):439-456.

18. Durham AL, Adcock IM. The relationship between COPD and lung cancer. Lung Cancer. 2015;90(2):121-127.

19. Loganathan RS, Stover DE, Shi W, et al. Prevalence of COPD in women compared to men around the time of diagnosis of primary lung cancer. Chest. 2006;129(5):1305-1312.

20. Young RP, Hopkins RJ, Christmas T, Black PN, Metcalf P, Gamble GD. COPD prevalence is increased in lung cancer, independent of age, sex and smoking history. Eur Respir J. 2009;34(2):380-386.

21. Dy SM, Sharkey P, Herbert R, Haddad K, Wu AW. Comorbid illnesses and health care utilization among Medicare beneficiaries with lung cancer. Crit Rev Oncol Hematol. 2006;59(3):218-225.

22. Birim O, Kappetein AP, Waleboer M, et al. Long-term survival after non-small cell lung cancer surgery: development and validation of a prognostic model with a preoperative and postoperative mode. JThorac Cardiovasc Surg. 2006;132(3):491-498.

23. Sekine Y, Suzuki H, Yamada Y, Koh E, Yoshino I. Severity of chronic obstructive pulmonary disease and its relationship to lung cancer prognosis after surgical resection. Thorac Cardiovasc Surg. 2013;61(2):124-130.

24. Gao YH, Guan WJ, Liu Q, et al. Impact of COPD and emphysema on survival of patients with lung cancer: a meta-analysis of observational studies. Respirology. 2016;21(2):269-279.

25. Mattila T, Vasankari T, Kanervisto M, et al. Association between allcause and cause-specific mortality and the GOLD stages 1-4: a 30-year follow-up among Finnish adults. Respir Med. 2015;109(8):1012-1018.

26. de Torres JP, Wilson DO, Sanchez-Salcedo P, et al. Lung cancer in patients with chronic obstructive pulmonary disease: development and validation of the COPD lung cancer screening score. Am J Respir Crit Care Med. 2015;191(3):285-291.

27. Kovalchik SA, Tammemagi M, Berg CD, et al. Targeting of low-dose CT screening according to the risk of lung-cancer death. N Engl J Med. 2013;369(3):245-254.

28. Sekine Y, Katsura H, Koh E, Hiroshima K, Fujisawa T. Early detection of COPD is important for lung cancer surveillance. Eur Respir $J$. 2012;39(5):1230-1240. 
29. Gonzalez J, Marín M, Sánchez-Salcedo P, Zulueta JJ. Lung cancer screening in patients with chronic obstructive pulmonary disease. Ann Transl Med. 2016;4(8):160

30. Raymakers AJ, McCormick N, Marra CA, Fitzgerald JM, Sin D, Lynd LD. Do inhaled corticosteroids protect against lung cancer in patients with COPD? A systematic review. Respirology. 2017;22(1):61-70.

31. Liu JC, Yang TY, Hsu YP, et al. Statins dose-dependently exert a chemopreventive effect against lung cancer in COPD patients: a populationbased cohort study. Oncotarget. 2016;7(37):59618-59629.

32. Brunelli A, Charloux A, Bolliger CT, et al. ERS/ESTS clinical guidelines on fitness for radical therapy in lung cancer patients (surgery and chemo-radiotherapy). Eur Respir J. 2009;34(1):17-41.

33. Brunelli A, Kim AW, Berger KI, Addrizzo-Harris DJ. Physiologic evaluation of the patient with lung cancer being considered for resectional surgery: diagnosis and management of lung cancer, 3rd ed: American College of Chest Physicians evidence-based clinical practice guidelines. Chest. 2013;143(5 Suppl):e166S-e190S.

34. Vansteenkiste J, Crinò L, Dooms C, et al. 2nd ESMO Consensus Conference on Lung Cancer: early-stage non-small-cell lung cancer consensus on diagnosis, treatment and follow-up. Ann Oncol. 2014;25:1462-1474.

35. Nyman J, Johansson KA, Hultén U. Stereotactic hypofractionated radiotherapy for stage I non-small cell lung cancer--mature results for medically inoperable patients. Lung Cancer. 2006;51(1):97-103.

36. Onishi H, Shirato H, Nagata $\mathrm{Y}$, et al. Hypofractionated stereotactic radiotherapy (HypoFXSRT) for stage I non-small cell lung cancer: updated results of 257 patients in a Japanese multi-institutional study. J Thorac Oncol. 2007;2(7 Suppl 3):S94-S100.

37. Onishi H, Shirato H, Nagata Y, et al. Stereotactic body radiotherapy (SBRT) for operable stage I non-small-cell lung cancer: can SBRT be comparable to surgery? Int J Radiat Oncol Biol Phys. 2011;81(5):1352-1358

38. Lagerwaard FJ, Verstegen NE, et al. Outcomes of stereotactic ablative radiotherapy in patients with potentially operable stage I non-small cell lung cancer. Int J Radiat Oncol Biol Phys. 2012;83(1):348-353.

39. Grills IS, Mangona VS, Welsh R, et al. Outcomes after stereotactic lung radiotherapy or wedge resection for stage I non-small-cell lung cancer. J Clin Oncol. 2010;28(6):928-935.

40. Mokhles S, Verstegen N, Maat AP, et al. Comparison of clinical outcome of stage I non-small cell lung cancer treated surgically or with stereotactic radiotherapy: results from propensity score analysis. Lung Cancer. 2015;87(3):283-289.

41. Chang JY, Senan S, Paul MA, et al. Stereotactic ablative radiotherapy vs lobectomy for operable stage I non-small-cell lung cancer: a pooled analysis of two randomised trials. Lancet Oncol. 2015;16(6):630-637.

42. Palma D, Lagerwaard F, Rodrigues G, Haasbeek C, Senan S. Curative treatment of Stage I non-small-cell lung cancer in patients with severe COPD: stereotactic radiotherapy outcomes and systematic review. Int J Radiat Oncol Biol Phys. 2012;82(3):1149-1156.

43. Inoue $T$, Shiomi $H$, Oh RJ. Stereotactic body radiotherapy for Stage I lung cancer with chronic obstructive pulmonary disease: special reference to survival and radiation-induced pneumonitis. $J$ Radiat Res. 2015;56(4):727-734.

44. Takeda A, Kunieda E, Ohashi T, Aoki Y, Oku Y, Enomoto T et al. Severe COPD is correlated with mild radiation pneumonitis following stereotactic body radiotherapy. Chest. 2012;141(4):858-866.

45. Takeda A, Enomoto T, Sanuki N, et al. Reassessment of declines in pulmonary function $\geq 1$ year after stereotactic body radiotherapy. Chest. 2013;143(1):130-137.

46. Guckenberger M, Kestin LL, Hope AJ, et al. Is there a lower limit of pretreatment pulmonary function for safe and effective stereotactic body radiotherapy for early-stage non-small cell lung cancer? J Thorac Oncol. 2012;7(3):542-551.

47. Jain S, Poon I, Soliman H, et al. Lung stereotactic body radiation therapy (SBRT) delivered over 4 or 11 days: a comparison of acute toxicity and quality of life. Radiother Oncol. 2013;108(2):320-325.

48. Rowell NP, Williams CJ. Radical radiotherapy for stage I/II non-small cell lung cancer in patients not sufficiently fit for or declining surgery (medically inoperable): a systematic review. Thorax. 2001;56(8):628-638.
49. Howington JA, Blum MG, ChangAC, Balekian AA, Murthy SC. Treatment of stage I and II non small cell lung cancer: diagnosis and management of lung cancer, 3rd ed: American College of Chest Physicians evidence-based clinical practice guidelines. Chest. 2013;143(5 Suppl):e278S-e313S.

50. Zhai R, Yu X, Shafer A, Wain JC, Christiani DC. The impact of coexisting COPD on survival of patients with early-stage non-small cell lung cancer undergoing surgical resection. Chest. 2014;145(2):346-353.

51. Kim ES, KimYT, Kang CH, et al. Prevalence of and risk factors for postoperative pulmonary complications after lung cancer surgery in patients with early-stage COPD. Int J Chron Obstruct Pulmon Dis. 2016;11:1317-1326.

52. British Thoracic Society; Society of Cardiothoracic Surgeons of Great Britain and Ireland Working Party. BTS guidelines: guidelines on the selection of patients with lung cancer for surgery. Thorax. 2001;56(2):89-108.

53. Kearney DJ, Lee TH, Reilly JJ, DeCamp MM, Sugarbaker DJ. Assessment of operative risk in patients undergoing lung resection. Importance of predicted pulmonary function. Chest. 1994;105(3):753-759.

54. Filaire M, Bedu M, Naamee A, et al. Prediction of hypoxemia and mechanical ventilation after lung resection for cancer. Ann Thorac Surg. 1999;67(5):1460-1465.

55. Global Strategy for the Diagnosis, Management and Prevention of COPD, Global Initiative for Chronic Obstructive Lung Disease (GOLD) 2017. Available from: http://goldcopd.org. Accessed May 27, 2017.

56. Robles AM, Shure D. Optimization of lung function before pulmonary resection: pulmonologists' perspectives. Thorac Surg Clin. 2004;14(3):295-304.

57. Yamanashi K, Marumo S, Shoji T, et al. The relationship between perioperative administration of inhaled corticosteroid and postoperative respiratory complications after pulmonary resection for non-small-cell lung cancer in patients with chronic obstructive pulmonary disease. Gen Thorac Cardiovasc Surg. 2015;63(12):652-659.

58. Nakagawa M, Tanaka H, Tsukuma H, Kishi Y. Relationship between the duration of the preoperative smoke-free period and the incidence of postoperative pulmonary complications after pulmonary surgery. Chest. 2001;120(3):705-710.

59. Barrera R, Shi W, Amar D, et al. Smoking and timing of cessation: impact on pulmonary complications after thoracotomy. Chest. 2005;127(6):1977-1983.

60. Groth SS, Whitson BA, Kuskowski MA, Holmstrom AM, Rubins JB, Kelly RF. Impact of preoperative smoking status on postoperative complication rates and pulmonary function test results 1-year following pulmonary resection for non-small cell lung cancer. Lung Cancer. 2009;64(3):352-357.

61. Divisi D, Di Francesco C, Di Leonardo G, Crisci R. Preoperative pulmonary rehabilitation in patients with lung cancer and chronic obstructive pulmonary disease. Eur J Cardiothorac Surg. 2013;43(2):293-296.

62. Nagarajan K, Bennett A, Agostini P, Naidu B. Is preoperative physiotherapy/pulmonary rehabilitation beneficial in lung resection patients? Interact Cardiovasc Thorac Surg. 2011;13(3):300-302.

63. Jeon JH, Kang CH, Kim HS, et al. Video-assisted thoracoscopic lobectomy in non-small-cell lung cancer patients with chronic obstructive pulmonary disease is associated with lower pulmonary complications than open lobectomy: a propensity score-matched analysis. Eur J Cardiothorac Surg. 2014;45(4):640-645.

64. Oparka J, Yan TD, Ryan E, Dunning J. Does video-assisted thoracic surgery provide a safe alternative to conventional techniques in patients with limited pulmonary function who are otherwise suitable for lung resection? Interact Cardiovasc Thorac Surg. 2013;17(1):159-162.

65. Fishman A, Martinez F, Naunheim K, et al. A randomized trial comparing lung-volume-reduction surgery with medical therapy for severe emphysema. N Engl J Med. 2003;348(21):2059-2073.

66. Naunheim KS, Wood DE, Mohsenifar Z et al. Long-term follow-up of patients receiving lung-volume-reduction surgery versus medical therapy for severe emphysema by the National Emphysema Treatment Trial Research Group. Ann Thorac Surg. 2006;82(2):431-443.

67. Choong CK, Meyers BF, Battafarano RJ, et al. Lung cancer resection combined with lung volume reduction in patients with severe emphysema. J Thorac Cardiovasc Surg. 2004;127(5):1323-1331. 
68. Vaughan P, Oey I, Nakas A, Martin-Ucar A, Edwards J, Waller D. Is there a role for therapeutic lobectomy for emphysema? Eur J Cardiothorac Surg. 2007;31(3):486-490.

69. Baldi S, Ruffini E, Harari S, et al. Does lobectomy for lung cancer in patients with chronic obstructive pulmonary disease affect lung function? A multicenter national study. J Thorac Cardiovasc Surg. 2005;130(6):1616-1622.

70. Rapicetta C, Tenconi S, Voltolini L, Luzzi L, Scala V, Gotti G. Impact of lobectomy for non-small-cell lung cancer on respiratory function in octogenarian patients with mild to moderate chronic obstructive pulmonary disease. Eur J Cardiothorac Surg. 2011;39(4):555-559.
71. Li SJ, Zhou XD, Huang J, Liu J, Tian L, Che GW. A systematic review and meta-analysis-does chronic obstructive pulmonary disease predispose to bronchopleural fistula formation in patients undergoing lung cancer surgery? J Thorac Dis. 2016;8(7):1625-1638.

72. Takeda K, Yamasaki A, Igishi T, Kawasaki Y, Ito-Nishii S, Izumi H et al. Frequency of Epidermal Growth Factor Receptor mutation in smokers with lung cancer without pulmonary emphysema. Anticancer Res. 2017;37(2):765-771.

73. Usui K, Ushijima T, Tanaka Y, et al. The frequency of Epidermal Growth Factor Receptor mutation of non-small cell lung cancer according to the underlying pulmonary diseases. Pulm Med. 2011;2011:290132.
Lung Cancer: Targets and Therapy

\section{Publish your work in this journal}

Lung Cancer: Targets and Therapy is an international, peer-reviewed, open access journal focusing on lung cancer research, identification of therapeutic targets and the optimal use of preventative and integrated treatment interventions to achieve improved outcomes, enhanced survival and quality of life for the cancer patient. Specific topics covered in the journal include: Epidemiology, detection and screening Cellular research and biomarkers; Identification of biotargets and agents with novel

Submit your manuscript here: https://www.dovepress.com/lung-cancer-targets--therapy-journa
Dovepress

mechanisms of action; Optimal clinical use of existing anticancer agents, including combination therapies; Radiation and surgery; Palliative care; Patient adherence, quality of life, satisfaction; Health economic evaluations. The manuscript management system is completely online and includes a very quick and fair peer-review system. Visit http://www.dovepress.com/testimonials.php to read real quotes from published authors. 